\title{
An empirical study on factors affecting e-commerce adoption among SMEs in west Malaysia
}

\author{
Seng Chee Lima*, Seng Poh Lim ${ }^{\mathrm{b}}$ and Numtip Trakulmaykee
}

${ }^{a, b}$ Faculty of Information and Communication Technology, Universiti Tunku Abdul Rahman, Jalan Universiti, Bandar Barat, 31900 Kampar, Perak, Malaysia

${ }^{c}$ Faculty of Science, Prince of Songkla University, 15 Karnjanavanit Road, Hatyai, Songkhla, 90112, Thailand

\section{CH R O N I C L E A B S T R A C T}

Article history:

Received: November 26, 2017

Received in revised format:

March 31, 2018

Accepted: April 4, 2018

Available online:

April 5, 2018

Keywords:

Adoption

e-Commerce

Small and Medium Enterprises

Developing Countries

\begin{abstract}
Small and Medium Enterprises (SMEs) play a major role in most developing countries because they are able to improve and develop the economy. e-Commerce is also an important topic in various research fields as it brings about benefits to these countries. However, the adoption of eCommerce by SMEs in developing countries is low due to several factors. Therefore, a parsimony framework has been proposed to investigate the factors which influence the adoption of e-Commerce among SMEs in West Malaysia. Three factors are considered in this research, namely Perceived Barriers, Organization Readiness, and Competitor Pressures. Questionnaires were used for data collection while SmartPLS was used to analyze the data. The results showed that Perceived Barriers contain negative significant influence on the adoption of e-Commerce among mediumsized SMEs, but not for small-sized SMEs. Organization Readiness shows a huge difference between small and medium-sized SMEs. Competitor Pressures are important for both small and medium-sized SMEs. In conclusion, the results obtained will assist and enable stakeholders to restructure e-Commerce applications which fulfill the needs of their organization and therefore, increase the effectiveness of the organization.
\end{abstract}

\section{Introduction}

In recent years, Electronic Commerce (e-Commerce) has become an important topic in various research fields such as technology, management, business, and marketing (Hashim \& Noor, 2014). As highlighted in previous studies, e-Commerce is able to bring about benefits for developing countries (Downing, 2006; Kartiwi \& MacGregor, 2007; Oliveira \& Martins, 2010). However, the adoption and development of e-Commerce for developing countries is slow due to differences in cultural background, legal structures, economics, infrastructures, and financial institutions (Kurnia et al., 2015). Hence, developing countries are still unable to fully utilize the benefits of e-Commerce (Kshetri, 2008).

Web pages and e-mails are widely adopted as e-Commerce applications in Malaysia (Hashim \& Che Senik; Marimuthu et al., 2011; Pearson \& Grandon, 2004; Megaravalli, 2017). These simple e-Commerce applications are popular among Small and Medium Enterprises (SMEs) because they contain

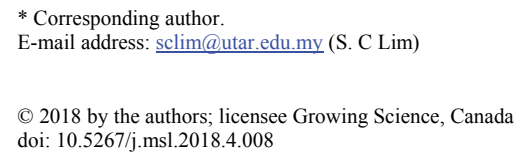


transaction functionalities (Hashim \& Noor, 2014). A number of studies related to e-Commerce adoption are unable to serve as the generic model for other countries due to factors stated previously (Sanjeev Dewan \& Kraemer, 2000). There are some researchers who claimed that research findings on a particular issue may not be applicable to other countries (Dewan \& Kraemer, 1998; Shah et al., 2013). This is because SMEs in developing countries contain different socio-economic backgrounds (Kshetri, 2008), business practices, cultural differences and challenges. It will indirectly cause a significant difference in the adoption of e-Commerce for a particular country. In addition, there are various factors which influence the innovation adoption (Kartiwi \& MacGregor, 2007; Ogundana et al., 2017). Besides, generalization results and different views can also affect the decision (Dewan \& Kraemer, 1998). This highlights a research gap where previous studies only focused on certain countries.

The significance of doing this research is to assist business stakeholders (business owners and top management personnel) to make informed decisions related to different types of e-Commerce technology and applications which can impact their organizations positively. A comprehensive and proper evaluation scheme can be devised based on the findings. Hence, SMEs will be more aware of internal and external challenges. Therefore, the motivation for conducting this research is to investigate the current status level of e-Commerce and factors which influence the adoption of e-Commerce among SMEs. The output will be able to contribute towards the adoption and diffusion research works with recent trends of e-Commerce, especially in developing countries.

The paper is structured as follows; Section 2 reviews background information and problem statements, Section 3 describes the research model formulation, Section 4 discusses the research methodology, Section 5 presents analysis and discussion while the last section provides conclusion, recommendations and possible future studies.

\section{Literature Review}

This section presents discussion on background information and problem statements related to this research.

\subsection{Background Information}

Generally, SMEs plays important and major roles in most developing countries. They generally boost a country's economic development. A majority of the business establishments in Malaysia are constituted by SMEs, at a rate of $99.2 \%$ (NSDC, 2014). In addition, SMEs contribute to $19 \%$ of the exports (NSDC, 2014), around 32\% of the Gross Domestic Product (GDP), and create 59\% of the total employment towards the Malaysian market. In July 2013, the National SMEs Development Council (NSDC) redefined new SMEs due to changes in the economy such as price inflation, business structure and trends since 2005 .

\subsection{Problem Statements}

In 2012, the Association of Chinese Chamber of Commerce and Industries Malaysia conducted a survey to investigate the problems and issues faced by SMEs in terms of innovation and human capital, among others. The survey report showed that e-Commerce adoption is quite low, which is only $28 \%$ (Bernama, 2012), which did not reach the minimum target (Saleh \& Ndubisi, 2006).

Although the adoption of e-Commerce is quite low, it still contains several potential approaches that can increase usage and enhance the fundamental level of e-Commerce mechanisms (Alamer et al., 2015). For the past decade, the Internet has been used as the new alternative medium (Thulani et al., 2010) to conduct the business activities such as expanding the market (Sin Tan et al., 2010; Turban et al., 2000), increasing the ability to compete (Iacovou et al., 1995; Turban \& Gehrke, 2000), providing 
better customer services and new business opportunities (Downing, 2006; Iacovou et al., 1995; Sin Tan et al., 2010; Turban et al., 2000), as well as accessing market information (Gunasekaran \& Ngai, 2005; Sin Tan et al., 2010).

Basically, the fundamentals of e-Commerce are to improve internal communication processes and assist the management in optimizing resources by increasing the efficiency of organizations. However, SMEs that have adopted e-Commerce face higher expectations. In addition to guiding them in carrying out marketing activities via websites and e-mails, e-Commerce possesses transactional capabilities ( Hashim \& Mat, 2012). The capabilities should be able to help them in reducing operational costs with minimal capital layout and they can turn to automated processes which can reduce routine jobs.

\section{Research Model Formulation}

There are several trends of adoption in the research stream. This research only considers three streams as stated below:

i. Assess factors based on various aspects which include innovative characteristics (Rogers, 2003) and skills, IT knowledge, management attitudes, trust, gender, ICT infrastructures, and security that can lead to innovative adoption.

ii. Compare and contrast between the adopter and non-adopter usage of e-Commerce applications, such as emails, portals, websites, and virtual private network. Besides these, Aziz and Jamali (2013) also studied and compared the characteristics of e-Commerce applications for Iranian SMEs.

iii. Post-adoption and impact of e-Commerce is shown in the study conducted by some researchers (Bordonaba-Juste et al., 2012; Zhu \& Kraemer, 2005). Their studies are based on the concept discussed in (i). Sila, (2013) stated that although various study factors have been investigated, the contexts of these factors are applicable. In fact, some of these contexts are useful and able to influence the creation of a successful system. Unfortunately, these factors are often overlooked.

Technology Organization Environment (TOE) is one of the popular frameworks in Information System (IS) research works (Tornatzky \& Fleischer, 1990). This framework is applied in various applications and research works such as Electronic Data Interchange (EDI) adoption (Iacovou et al., 1995; Musawa \& Wahab, 2012), e-Market (Duan et al., 2012), e-Business (Zhu et al., 2003), and e-Commerce (Ahmad et al., 2015; Kurnia et al., 2015).

TOE framework contains the environmental context, which is new and not found in other IS models such as the Technology Acceptance Model (TAM) (Davis, 1989). The environmental context indicates the opportunities and constraints in technological innovation. Furthermore, the technological context is flexible compared to other IS models because any technological characteristics can be grouped together.

\subsection{Perceived Barriers}

Perceived Barriers is one of the favoured study variables in both diffusion and adoption studies. This variable contains negative perception of technological implementation, which discourages the adoption of technological innovation. When technology becomes more sophisticated and the perceived obstacle is relevant, the adoption process becomes complicated and difficult to implement due to high costing (Martins \& Oliveira, 2008). 
The adoption process may require a substantial degree of technical and organizational resources for a smooth transition (Hong \& Zhu, 2006). As a result, this will increase the level of resistance for adoption. It is important to know the barriers before the implementation. This is to avoid the increase in the level of resistance for adoption which can decrease the likelihood for adoption.

Previous works also showed that Perceived Barriers is a significant variable for the adoption. This is shown in e-Commerce adoption and migration conducted by Hong and Zhu (2006) and Enterprise Resource Planning (ERP) adoption context conducted by Pan and Jang (2008). Therefore, Hypothesis 1 (H1) is stated as follows:

H1: Perceived Barriers is negatively related to e-Commerce adoption

\subsection{Organization Readiness}

Generally, Organization Readiness is linked to available resources in the organization. In the study of EDI adoption, Iacovou et al. (1995) categorized the Organization Readiness into technological and financial resources. In SMEs, resources are very important for an organization to sustain its business. In the study of innovation business through e-Commerce, Hussin and Noor (2005) stated that technological knowledge is one of the successful factors that can influence e-Commerce adoption. Moreover, Wang and Tsai (2002) mentioned that the lack of cost is another factor. Also, the lack of readiness will increase the implementation costs. Ramdani et al. (2009) concluded that the lack of financial and technical resources has been identified as inhibitor factors that can hinder the growth of small-sized organizations. Organization which lacks readiness will less likely adopt the innovation (Alam et al., 2011). Therefore, Hypothesis $2(\mathrm{H} 2)$ is stated as follows:

\section{H2: Organization Readiness is positively related to e-Commerce adoption}

\subsection{Competitor Pressures}

The decision of an organization to adopt new innovative technologies can be affected by some external factors such as uncertain environment, customers, suppliers, trading partners and governments (Ifinedo, 2011a). Intensive competition can lead to a new way of conducting businesses, which includes using new technology. For instance, the market position concepts are very important in a competitive market because the organization can compare the products and services with potential competitors. Besides using the conventional marketing techniques, the organization can adopt e-Commerce applications because they can ease the communication process and decrease pressure. Previous works have claimed that the Competitor Pressures have a significant impact on the adoption such as the study of e-commerce in the context of New Zealand conducted by (Al-Qirim, 2007), the context of Internet/ e-Business conducted by (Ifinedo, 2011a) and in the study of adoption for enterprise application conducted by (Ramdani et al., 2013). Hence, Hypothesis 3 (H3) is stated as follows:

H3: Competitor Pressures are positively related to e-Commerce adoption.

\section{Methodology}

A quantitative survey method was employed for the purpose of this research. The respondents consisted of SMEs manufacturers from West Malaysia. Their information was retrieved from SME Corporation Malaysia agency (Smeinfo, 2012). Based on the database, there are 17,165 registered enterprises. For the purpose of this research, the respondents were selected randomly from the database. Based on the general rule for sample size estimation, the ratio of the minimum number of respondent to the number of predictor variables is 5 to 1 . As stated by Hair et al., (1992), 'The acceptable range is from 5 to 15.' 
In addition, there are three variables as opposed to one dependent variable in the proposed model. Therefore, the ratio of 10 to 1 with the minimum sample size of 30 was utilized for this research.

The measurement scales were adapted from previous studies (Ainin \& Noorismawati, 2003; Alam et al., 2004; Iacovou et al., 1995; Ifinedo, 2011a) which ranges from 1 to 7 on a Likert Point Scale (Scale 1 indicates 'strongly disagree' while Scale 7 indicates 'strongly agree').

The data collection process lasted for four months. A total of 1200 self-administered sets of questionnaires were distributed to the respondents but only 310 sets of questionnaires were received. From the collected data, only adopters were selected while non-adopters and potential adopters were excluded. Therefore, 217 sets were used for data analysis (18\% of the total respondent rate) while the sample size also reached the minimum requirement. SmartPLS v2.0 was used to analyze the data $(\mathrm{GmbH}, 2015)$.

\section{Analysis and Discussion}

This section demonstrates the analysis and discussion based on the collected data.

\subsection{Analysis}

The analysis will be divided into three parts, which include Descriptive Data, Convergent Validity, and Discriminant Validity.

\subsubsection{Descriptive Data}

Table 1 presents the data analysis of 149 respondents of small-sized SMEs and 68 respondents of medium-sized SMEs. It shows the descriptive values of the respective variables (Adoption, Perceived Barriers, Organization Readiness, and Competitor Pressures) between the small-sized and mediumsized SMEs.

\section{Table 1}

Descriptive Data

\begin{tabular}{|c|c|c|c|c|c|c|}
\hline \multirow{2}{*}{\multicolumn{2}{|c|}{ Variables }} & \multicolumn{2}{|c|}{ Mean } & \multicolumn{2}{|c|}{ Std Deviation } & \multirow{3}{*}{$\begin{array}{c}\begin{array}{c}\text { Cronbach's } \\
\text { Alpha }\end{array} \\
0.93\end{array}$} \\
\hline & & \multirow{2}{*}{$\frac{\text { Small }}{4.56}$} & \multirow{2}{*}{$\frac{\text { Medium }}{4.72}$} & \multirow{2}{*}{$\frac{\text { Small }}{1.14}$} & \multirow{2}{*}{$\frac{\text { Medium }}{1.20}$} & \\
\hline Dependent & Adoption & & & & & \\
\hline \multirow{3}{*}{ Independent } & Perceived Barriers & 4.54 & 4.24 & 1.16 & 1.23 & 0.94 \\
\hline & $\begin{array}{l}\text { Organization Readi- } \\
\text { ness }\end{array}$ & 4.59 & 4.79 & 1.15 & 1.25 & 0.94 \\
\hline & $\begin{array}{l}\text { Competitor Pres- } \\
\text { sures }\end{array}$ & 4.55 & 4.68 & 1.00 & 1.04 & 0.81 \\
\hline
\end{tabular}

For Adoption, it shows that medium-sized SMEs possess higher tendency to adopt e-Commerce applications compared to small-sized SMEs. As shown in Table 1, the mean of Perceived Barriers for medium-sized SMEs is only 4.24, which is the lowest compared to other independent variables. The value indicates that technical issues are not a threat for the Adoption variable.

\subsubsection{Convergent Validity}

Three elements were used to assess the convergent validity. These included Main Loading (ML), Average Variance Extracted (AVE), and Composite Reliability (CR). Table 2 illustrates the measurement model for different elements and variables. For a Main Loading (ML) value, it must be greater or equal to 0.50 . Otherwise, any value of the item which is less than the benchmark value will be discarded from the respective constructors. The respective constructors are the values of PBar as shown in Table 2 . Besides that, the values of AVE must be greater than 0.50 (Urbach \& Ahlemann, 2010). In addition, the values of Cronbach's Alpha as shown in Table 1 and CR as shown in Table 2 were used to measure 
the internal consistency for the respective constructors. Although it is suggested that the benchmark value must be at least 0.70 , a higher $\mathrm{CR}$ value is preferred.

Table 2

Measurement Model

\begin{tabular}{|c|c|c|c|c|c|c|c|}
\hline \multirow[t]{2}{*}{ Variable } & \multirow[t]{2}{*}{ Items } & \multicolumn{2}{|c|}{ Main Loading } & \multicolumn{2}{|c|}{$\begin{array}{l}\text { Average Variance Ex- } \\
\text { tracted }\end{array}$} & \multicolumn{2}{|c|}{ Composite Reliability } \\
\hline & & Small & Medium & Small & Medium & Small & Medium \\
\hline \multirow[t]{8}{*}{ Adoption } & ADT1 & 0.79 & 0.85 & 0.64 & 0.76 & 0.93 & 0.96 \\
\hline & ADT2 & 0.80 & 0.86 & & & & \\
\hline & ADT3 & 0.75 & 0.86 & & & & \\
\hline & ADT4 & 0.81 & 0.88 & & & & \\
\hline & ADT5 & 0.80 & 0.87 & & & & \\
\hline & ADT6 & 0.81 & 0.88 & & & & \\
\hline & ADT7 & 0.82 & 0.86 & & & & \\
\hline & ADT8 & 0.81 & 0.89 & & & & \\
\hline \multirow{10}{*}{$\begin{array}{l}\text { Perceived } \\
\text { Barriers }\end{array}$} & PBar1 & 0.76 & 0.78 & 0.60 & 0.70 & 0.93 & 0.96 \\
\hline & PBar2 & 0.76 & 0.81 & & & & \\
\hline & PBar3 & 0.81 & 0.86 & & & & \\
\hline & PBar4 & 0.87 & 0.86 & & & & \\
\hline & PBar5 & 0.84 & 0.88 & & & & \\
\hline & PBar6 & 0.74 & 0.84 & & & & \\
\hline & PBar7 & 0.63 & 0.81 & & & & \\
\hline & PBar8 & 0.79 & 0.81 & & & & \\
\hline & PBar9 & 0.72 & 0.84 & & & & \\
\hline & PBar10 & - & 0.84 & & & & \\
\hline \multirow{4}{*}{$\begin{array}{c}\text { Organization } \\
\text { Readiness }\end{array}$} & OR1 & 0.91 & 0.95 & 0.84 & 0.89 & 0.95 & 0.97 \\
\hline & OR2 & 0.92 & 0.95 & & & & \\
\hline & OR3 & 0.92 & 0.95 & & & & \\
\hline & OR4 & 0.92 & 0.93 & & & & \\
\hline \multirow{4}{*}{$\begin{array}{l}\text { Competitor } \\
\text { Pressures }\end{array}$} & CP1 & 0.56 & 0.68 & 0.61 & 0.74 & 0.86 & 0.92 \\
\hline & CP2 & 0.81 & 0.92 & & & & \\
\hline & CP3 & 0.88 & 0.93 & & & & \\
\hline & CP4 & 0.83 & 0.90 & & & & \\
\hline
\end{tabular}

As shown in Table 2, the item named PBar10 was dropped from small-sized SMEs because it did not surpass the benchmark value. The ML values of medium-sized SMEs are higher than the benchmark value. For AVE values, the range is from 0.60 to 0.84 for small-sized SMEs and 0.70 to 0.89 for medium-sized SMEs. As for the CR values of each respective construct, they range from 0.92 to 0.97 , which are higher than the benchmark value. Based on the given benchmark values, the variables have fulfilled the convergent validity.

\subsubsection{Discriminant Validity}

Two requirements were used to assess the discriminant validity. Firstly, the diagonal values should be greater or equal to 0.5 . Secondly, the diagonal values should be higher than all the values reflected in the rows and columns (Ifinedo, 2011b). Table 3 and Table 4 show the discriminant validity for smallsized and medium-sized SMEs. The bold text shown in the tables below represents the square root of AVE values.

Table 3

Discriminant Validity for Small SMEs

\begin{tabular}{ccccc}
\hline Variable & Adoption & Perceived Barriers & $\begin{array}{c}\text { Organization Read- } \\
\text { iness }\end{array}$ & $\begin{array}{c}\text { Competitor Pres- } \\
\text { sures }\end{array}$ \\
\hline Adoption & 0.80 & & & \\
Perceived Barriers & -0.12 & 0.77 & & \\
Organization Readiness & 0.59 & -0.13 & 0.92 & 0.78 \\
Competitor Pressures & 0.48 & 0.25 & 0.42 & \\
\hline
\end{tabular}


Table 4

Discriminant Validity for Medium SMEs

\begin{tabular}{ccccc}
\hline Variable & Adoption & Perceived Barriers & $\begin{array}{c}\text { Organization Read- } \\
\text { iness }\end{array}$ & $\begin{array}{c}\text { Competitor Pres- } \\
\text { sures }\end{array}$ \\
\hline Adoption & 0.87 & & & \\
Perceived Barriers & -0.26 & 0.84 & & \\
Organization Readiness & 0.55 & -0.23 & 0.94 & 0.86 \\
Competitor Pressures & 0.64 & -0.07 & 0.46 & \\
\hline
\end{tabular}

The results in Table 3 and Table 4 show that the requirements have been fulfilled. This indicates that the data obtained are suitable for both models.

\subsection{Discussion}

As highlighted in the previous section, Adoption is the dependent variable while Perceived Barriers, Organization Readiness and Competitor Pressures are three independent variables in this research. Table 5 indicates the results for the model.

Table 5

Path Analysis and T-Value

\begin{tabular}{ccccccccc}
\hline Path & \multicolumn{2}{c}{ Beta Value $(\beta)$} & \multicolumn{2}{c}{ Standard Deviation } & \multicolumn{2}{c}{ t-value } & \multicolumn{2}{c}{ Decision } \\
\cline { 2 - 8 } & $\mathrm{S}$ & $\mathrm{M}$ & $\mathrm{S}$ & $\mathrm{M}$ & $\mathrm{S}$ & $\mathrm{M}$ & $\mathrm{S}$ & $\mathrm{M}$ \\
\hline $\begin{array}{c}\text { Perceived Barriers }-> \\
\text { Adoption }\end{array}$ & -0.16 & -0.16 & 0.12 & 0.09 & 1.34 & $1.84^{*}$ & $\times$ & $\checkmark$ \\
$\begin{array}{c}\text { Organization Readiness -> } \\
\text { Adoption }\end{array}$ & 0.42 & 0.29 & 0.07 & 0.15 & $5.70^{* *}$ & $1.96^{*}$ & $\checkmark$ & $\checkmark$ \\
$\begin{array}{c}\text { Competitor Pressures } \\
\quad>\text { Adoption }\end{array}$ & 0.35 & 0.50 & 0.08 & 0.12 & $4.46^{* *}$ & $4.29^{* *}$ & $\checkmark$ & $\checkmark$ \\
\hline
\end{tabular}

Significant level: ** $\mathrm{p}<0.01 ;{ }^{*} \mathrm{p}<0.05 ; \mathrm{S}=$ small, $\mathrm{M}=$ medium; $\mathbf{x}$ - Not Supported; $\checkmark$ - Supported

Percentage of variances $\left(\mathrm{R}^{2}\right)$ is used to indicate the predictive power of the model. It can reflect the significant relationship between the dependent and independent variables in the model. For small-sized SMEs, the $\mathrm{R}^{2}$ is $0.44(44 \%)$. As shown in Table 5, Organization Readiness and Competitor Pressures are two important variables for the small-sized SMEs. As for medium-sized SMEs, the $\mathrm{R}^{2}$ is $0.52(52 \%)$, which is slightly higher than that of small-sized SMEs. This proves that all three independent variables are significant for medium sized SMEs. "Goodness of Fit (GoF) is used to determine the overall predictive power of the model by accounting for the performance of both measurement and structural parameters" (Thien \& Razak, 2013). The formula is: square root of mean of (AVE) * mean of (R2), or as follows:

$$
G o F=\sqrt{\overline{A V E}} \times \sqrt{\overline{R^{2}}}
$$

For small-sized SMEs, the Beta Value for Organization Readiness is 0.42 while the t-value is 5.70. As for Competitor Pressures, the Beta Value and t-value are 0.35 and 4.46, respectively. For medium-sized SMEs, the Beta Value and t-value for Perceived Barriers are -0.16 and 1.84, respectively. This reflects a negative relationship with Adoption. Organization Readiness contains a Beta Value of 0.29 and tvalue of 1.96. As for Competitor Pressures, the Beta Value and t-value are 0.40 and 4.29, respectively. The GoF value for small SMEs is 0.541, which surpassed the baseline value. Besides that, the GoF value for medium SMEs is 0.631 , which also surpassed the baseline value. This indicates that both models contain better and excellent exploratory power.

Both of the results revealed that the model has an excellent exploratory power in comparison to the baseline values as recommended by Wetzels et al. (Wetzels et al., 2009) in which the value of 0.1 is indicated as small, 0.25 indicated as medium and 0.36 indicated as large. Perceived Barriers is has a 
significantly negative influence on the adoption of medium-sized SMEs. However, it does not influence the adoption of e-Commerce among small-sized SMEs. It shows that small-sized SMEs contain fewer technical barriers compared to medium-sized SMEs. This is because small-sized SMEs usually remain at the fundamental level of e-Commerce. For example, email and website are the most favoured eCommerce applications adopted by small-sized SMEs. They do not need extra allocation to hire employees to perform maintenance because there are free services on the Internet (Omar et al., 2011). Thus, this will not increase the technical barriers. Medium-sized SMEs are different compared to smallsized SMEs because when an organization expands in size, it needs to invest more in research and development. This will increase the cost and technical intensity in order to perform daily operations. As a result, the resistance level towards e-Commerce adoption will increase.

Organization Readiness portrays significant differences between small-sized and medium-sized SMEs. For small-sized SMEs, they need to consider reallocation of resources by researching on the feasibility due to scarcity of resources. As for medium-sized SMEs, they seldom encounter this problem. One of the possible reasons is that medium-sized SMEs are more innovative and capable of implementing new technologies as they possess sufficient resources and skilled workers.

Competitor Pressures is important for both small and medium-sized SMEs. By using e-Commerce, they will be able to increase the distribution of channels and improve the communication process. It can also prove to their competitors that they have technical capabilities. Furthermore, it also shows that SMEs are "high tech" and this will enable them to place themselves in a better market position within the various industries.

Based on this research, it can be deduced that technological characteristics of Perceived Barriers are not significant for small-sized SMEs. The results shown in Table 5 may not be able to indicate that small-sized SMEs did not encounter Perceived Barriers and need to be consistent based on previous works. The technology may not have met the needs of small-sized SMEs. The inconsistent results may also be due to the definition and measurement items of the various factors.

\section{Conclusion and Future Studies}

This section highlights and discusses the conclusion and possible future studies related to this research.

\subsection{Conclusion}

The TOE framework has been applied and employed in producing this research to investigate the current status of e-Commerce and factors which influence the adoption of e-Commerce among SMEs in West Malaysia. The results show that Organization Readiness and Competitor Pressures are two important variables for small-sized SMEs with the $\mathrm{R}^{2}$ of $0.44(44 \%)$. As for medium-sized SMEs, the $\mathrm{R}^{2}$ is $0.52(52 \%)$, which is slightly higher than that of small-sized SMEs. This results show that all three independent variables are significantly important for medium-sized SMEs.

In terms of research contributions, the results can serve as the benchmark for e-Commerce adoption and diffusion research in other developing countries. Besides that, these results will potentially encourage future explorations on different types of factors and variables related to research on e-Commerce adoption. This research also provides a holistic view for stakeholders along with adequate tools. Moreover, this can be used as a form of guidance to re-shape e-Commerce applications in order to be more versatile and useful. In addition, it also offers innovative ways to increase the effectiveness of an organization. 


\subsection{Potential Future Studies}

This research focused only on the manufacturing sector. The findings of this research may not be relevant in other sectors such as business-related services, tourism, transportation and hotel management. Furthermore, the model is also not applicable in East Malaysia due to geographical, socio-economic and cultural differences. On the hindsight, these differences can be considered as pre-cursors to future studies.

Besides that, future studies can also focus on highlighting the differences between adopter and nonadopter factors. In addition, other variables such as moderator and mediator can be included in future research. Future studies can be conducted to better understand the differences between these two major groups.

\section{Acknowledgement}

The authors would like to thank the anonymous referees for construction comments on earlier version of this paper.

\section{References}

Ahmad, S. Z., Abu Bakar, A. R., Faziharudean, T. M., \& Mohamad Zaki, K. A. (2015). An Empirical Study of Factors Affecting E-Commerce Adoption Among Small and Medium Sized Enterprises in A Developing Country: Evidence from Malaysia. Information Technology For Development, 21(4), $1-18$.

Ainin, S., \& Noorismawati, J. (2003, 2003). E-Commece Stimuli and Practie in Malaysia.

Al-Qirim, N. (2007). The Adoption of E-Commerce Communications and Applications Technologies in Small Businesses in New Zealand. Electronic Commerce Research and Applications, 6(4), 462473.

Alam, S. S., Ali, M. Y., \& Jani, M. F. M. (2011). An Empirical Study of Factors Affecting Electronic Commerce Adoption among SMEs in Malaysia. Journal Of Business Economics And Management Decision, 12(2), 375-399.

Alam, S. S., Khatibi, A., Sim Chloe Teah, W., \& Haque, A. (2004). Perceived Barriers of E-Commerce Expansion in The Electronic Manufacturing Companies in Malaysia. International Business \& Economics Research Journal, 3(10), 111-118.

Alamer, A. R. A., Salamon, H. B., Qureshi, M. I., \& Rasli, A. M. (2015). How do We Measure Corporate Social Responsibility of Islamic Banks through their Business Processes and Oriented Outcomes? International Journal of Economics and Financial Issues, 5.

Aziz, F. A., \& Jamali, N. (2013). Factors Inflencing the Level of Adoption in Electronic Commerce Among SMEs. International Journal of Information Technology \& Computer Science, 8(2), 105110.

Bernama. (2012). E-commerce adoption among SMEs remains low Retrieved from http://biz.thestar.com.my/news/story.asp?file=/2012/4/18/business $/ 11123341 \&$ sec=business

Bordonaba-Juste, V., Lucia-Palacios, L., \& Polo-Redondo, Y. (2012). Antecedents and Consequences of E-Business Adoption for European Retailers. Internet Research, 22(5), 532-550.

Davis, F. D. (1989). Perceived Usefulness, Perceived Ease of Use, and User Acceptance of Information Technology. MIS Quarterly, 13(3), 319-340.

Dewan, S., \& Kraemer, K. L. (1998). International dimensions of the productivity paradox. Communications of the ACM, 41(8), 56-62.

Dewan, S., \& Kraemer, K. L. (2000). Information technology and productivity: evidence from countrylevel data. Management Science, 46(4), 548-562.

Downing, R. E. (2006). The benefits and obstacles of E-commerce: Toward an understanding of adoption. Journal of Internet commerce, 5(2), 95-122. 
Duan, X., Deng, H., \& Corbitt, B. (2012). Evaluating The Critical Determinants for Adopting E-Market in Australian Small and Medium Sized Enterprises. Management Research Review, 35(3/4), 289308.

GmbH, S. (2015). [Support for SmartPLS 2.0.M3 ended].

Gunasekaran, A., \& Ngai, E. W. (2005). E-commerce in Hong Kong: an empirical perspective and analysis. Internet Research, 15(2), 141-159.

Hashim, N., \& Che Senik, Z. Mat Isa, R.; and Abdullah, N., 2011. SMEs' Characteristics of Ecommerce Adopters. Journal of Management and Science, 9(2), 1-18.

Hashim, N. A., \& Mat, N. (2012). At the Crossroad between Perceived and Proven Benefits of Ecommerce-A Case of Malaysian SMEs. Paper presented at the Annual Paris Business and Social Sciences Conference.

Hashim, N. A., \& Noor, S. M. (2014). An Investigation of Key Adoption of E-Commerce in Smes in Malaysia. Paper presented at the Proceedings of the 26th International Business Research Conference. April.

Hong, W., \& Zhu, K. (2006). Migrating to Internet Based E-Commerce: Factors Affecting ECommerce Adoption and Migration at The Firm Level. Information \& Management, 43(2), 204221.

Hussin, H., \& Noor, R. M. (2005). Innovating Business Through E-Commerce: Exploring The Willingness of Malaysian SMEs.

Iacovou, C. L., Benbasat, I., \& Dexter, A. S. (1995). Electronic Data Interchange and Small Organizations: Adoption and Impact of Technology. MIS Quarterly, 19(4), 465-485.

Ifinedo, P. (2011a). An Empirical Analysis of Factors Influencing Internet/E-Business Technologies Adoption By SMEs in Canada. International Journal of Information Technology \& Decision Making, 10(4), 731-766.

Ifinedo, P. (2011b). Internet/E-Business Technologies Acceptance in Canada's SMEs: An Exploratory Investigation. Internet Research, 21(3), 255-281.

Joseph F. Hair, J. R., Anderson, R. E., Tatham, R. L., \& Black, W. C. (1992). Multivariate Data Analysis With Readings. New York: Macmillian Publishing Company.

Kartiwi, M., \& MacGregor, R. C. (2007). Electronic commerce adoption barriers in small to mediumsized enterprises (SMEs) in developed and developing countries: A cross-country comparison. Journal of Electronic Commerce in Organizations (JECO), 5(3), 35-51.

Kshetri, N. (2008). Barriers to e-commerce and competitive business models in developing countries: A case study. Electronic Commerce Research and Applications, 6(4), 443-452.

Kurnia, S., Choudrie, J., Mahbubur, R. M., \& Alzougool, B. (2015). E-commerce Technology Adoption: A Malaysian Grocery SME Retail Sector Study. Journal of Business Research, 68(9), 1906-1918.

Marimuthu, M., Omar, A., Ramayah, T., \& Mohamad, O. (2011). Readiness to adopt E-business among SMEs in Malaysia: Antecedents and consequence. International Journal of E-Adoption (IJEA), 3(3), 1-19.

Martins, M. F. O., \& Oliveira, T. (2008). Determinants of Information Technology Diffusion: a Study at the Firm Level for Portugal. The Electronic journal Information Systems Evaluation, 11(1), 2734.

Megaravalli, A. (2017). Estimating growth of SMES using a logit model: Evidence from manufacturing companies in Italy. Management Science Letters, 7(3), 125-134.

Musawa, M. S., \& Wahab, E. (2012). The Adoption of Electronic Data Interchange (EDI) Technology by Nigerian SMEs: A Conceptual Framework. Journal of Business Management and Economics, 3(2), 55-68.

Ogundana, O., Okere, W., Ayomoto, O., Adesanmi, D., Ibidunni, S., \& Ogunleye, O. (2017). ICT and accounting system of SMEs in Nigeria. Management Science Letters, 7(1), 1-8.

Oliveira, T., \& Martins, M. F. (2010). Understanding e-business adoption across industries in European countries. Industrial Management \& Data Systems, 110(9), 1337-1354. 
Omar, A., Ramayah, T., Lin, L. B., \& Marimuthu, M. (2011). Determining Factors For The Usage Of Web-Based Marketing Applications By Small And Medium Enterprises (SMEs) In Malaysia. Journal of Marketing Development and Competitiveness, 5(2), 70-86.

Pan, M.-J., \& Jang, W.-Y. (2008). Determinants of the Adoption of Enterprise Resource Planning within the Technology Organization Environemnt Framework : Taiwan's Communication Industry. Journal of Computer Information system, 48(3), 94-102.

Pearson, J. M., \& Grandon, E. (2004). E-commerce adoption: perceptions of managers/owners of small and medium sized firms in Chile. The Communications of the Association for Information Systems, 13(1), 46.

Ramdani, B., Chevers, D., \& Williams, D. A. (2013). SMEs' Adoption of Enterprise Applications A Technology-Organisation-Environment Model. Journal of Small Business and Enterprise Development, 20(4), 735-753.

Ramdani, B., Kawalek, P., \& Lorenzo, O. (2009). Predicting SMEs’ Adoption of Enterprise Systems. Journal of Enterprise Information Management, 22(1/2), 10-24.

Rogers, E. M. (2003). Diffusion of innovations. Free Press. New York, 551.

Saleh, A. S., \& Ndubisi, N. O. (2006). An evaluation of SME development in Malaysia. International review of business research papers, 2(1), 1-14.

Shah, G. U. D., Bhatti, M. N., Iftikhar, M., Qureshi, M. I., \& Zaman, K. (2013). Implementation of technology acceptance model in e-learning environment in rural and urban areas of Pakistan. World Applied Sciences Journal, 27(11), 1495-1507.

Sila, I. (2013). Factors Affecting the Adoption of B2B E-Commerce Technologies. Electronic commerce research, 13(2), 199-236.

Sin Tan, K., Choy Chong, S., Lin, B., \& Cyril Eze, U. (2010). Internet-based ICT adoption among SMEs: Demographic versus benefits, barriers, and adoption intention. Journal of Enterprise Information Management, 23(1), 27-55.

Smeinfo (2012). [SMEInfo].

Thien, L. M., \& Razak, N. A. (2013). Academic Coping, Friendship Quality, and Student Engagement Associated with Student Quality of School Life: A Partial Least Square Analysis. Social Indicators Research, 112(3), 679-708.

Thulani, D., Tofara, C., \& Langton, R. (2010). Electronic commerce benefits and adoption barriers in small and medium enterprises in Gweru, Zimbabwe. Journal of Internet Banking and Commerce, $15(1), 1$.

Tornatzky, L. G., \& Fleischer, M. (1990). The processes of Technology Innovation: Lexington Books.

Turban, E. Lee., J., King, D., Chung, HM,(2000). Electronic Commerce: A Managerial Perspective. In: Prentice Hall, London.

Turban, E., \& Gehrke, D. (2000). Determinants of e-commerce website. Human Systems Management, 19(2), 111-120.

Urbach, N., \& Ahlemann, F. (2010). Structural Equation Modeling in Information Systems Research Using Partial Least Squares. Journal of Information technology theory and application, 11(2), 5-40.

Wang, J.-C., \& Tsai, K.-H. (2002). Factors in Taiwanese Firms'Decisions to Adopt Electronic Commerce: An Empirical Study. The World Economy, 25, 1145-1167.

Wetzels, M., Odekerken-Schröder, G., \& Van Oppen, C. (2009). Using PLS path modeling for assessing hierarchical construct models: Guidelines and empirical illustration. MIS Quarterly, 177195.

Zhu, K., \& Kraemer, K. L. (2005). Post Adoption Variations in Usage and Value of E-Business by Organization: Cross Country Evidence from the Retail Industry. Information Systems Research, 16(1), 61-84.

Zhu, K., Kramer, K., \& Xu, S. (2003). Electronic Business Adoption by European Firm: A Cross Country Assessment of the Facilitators and Inhibitors. European Journal of Information Systems, 2003(12), 251-268. 
(C) 2018 by the authors; licensee Growing Science, Canada. This is an open access article distributed under the terms and conditions of the Creative Commons Attribution (CC-BY) license (http://creativecommons.org/licenses/by/4.0/). 